\title{
In-situ hydrogen isotope analysis of pyroxenes in Precambrian gabbro
}

\author{
HIKARU YAGI ${ }^{1}$, SHOICH ITOH ${ }^{2}$, AKIRA ISHIKAWA ${ }^{1,3}$, \\ TAKAZO SHIBUYA ${ }^{3,}$ YUICHIRO UENO ${ }^{1,3,4}$
}

${ }^{1}$ Dept. of Earth and Planetary Sciences, Tokyo Institute of

Technology, Tokyo, Japan $(*$ correspondence:

yagi.h.ac@m.titech.ac.jp)

${ }^{2}$ Kyoto University, Kyoto, Japan

${ }^{3}$ Japan Agency for Marine-Earth Science and Technology, Yokosuka, Japan

${ }^{4}$ Earth-Life Science Institute (WPI-ELSI), Tokyo Institute of Technology, Tokyo, Japan

Hydrogen isotopic composition of present mantle is estimated from MORB glasses $\left(\delta D_{\text {vsmow }}=-80\right.$ to $-60 \%$; $[1$, $2])$, though the $\delta \mathrm{D}$ value of ancient mantle has not been estimated because of the lack of appropriate samples. Here, we report hydrogen isotopic composition of pyroxene in Precambrian gabbro in order to constrain hydrogen isotopic evolution of mantle through the history of the Earth. We have developed the analytical methods with secondary ion mass spectrometry adopted to measure hydrogen isotopic composition of pyroxene and applied to 3.2 Ga gabbro from Andover Intrusion, Western Australia, and 755 Ma gabbro from Mundine Dyke Swarm, Western Austrlia. In the $3.2 \mathrm{Ga}$ gabbro, metamorphic amphibole shows high $\delta \mathrm{D}$ value up to $+37 \%$, whereas diopside shows relatively low $\delta \mathrm{D}$ value from $-267 \%$ to $-50 \%$. The diopside includes small amphibole lamellae having $\delta \mathrm{D}$ value of $-106 \pm 13 \%$. The observed $\delta \mathrm{D}$ variation of the diopside can be partly explained by exchange with the deuterium-rich metamorphic fluid, though the secondary process cannot produce the low $\delta \mathrm{D}$ diopside, which show fractiontion trend against the co-existing amphibole lamellae exsolved from original $\mathrm{H}_{2} \mathrm{O}$-rich pyroxene. Based on mass-balance calculation, we estimate original $\delta \mathrm{D}$ value of pyroxene $(-160 \pm 55 \%)$. On the other hand, $755 \mathrm{Ma}$ pyroxenes in the gabbro dyke show mean $\delta \mathrm{D}$ value of $-214 \pm 27 \%$ for enstatite, whereas that of augites is $-193 \pm 17 \%$. Both of them do not show any sign of secondary modification of the $\delta \mathrm{D}$ value. As a result, the two Precambrian pyroxenes both show deuterium-depleted composition compared with modern MORB source mantle or Phanerozoic pyroxene. This indicates the presence of deuterium-depleted water source $(<-160 \%)$ in Precambrian mantle, which may represent primodial source [3] or subducted component [4]. 